\title{
Developing Expert System for Soil Stabilization under Flexible Pavement
}

\author{
Mahmood R. Mahmood, Ammar A. M. Shubber, Asaad Hamdan Maryoosh
}

\begin{abstract}
Experts are, generally, busy and few in number. Getting them to work any time and in several locations is difficult, if not impossible, and requires time, cost and stress. Soil stabilization and modification represent an excellent domain for the development of an expert system, which contains a knowledge base of heuristic rules about types and remedies of stabilization. Thus, an Expert system program is a suitable solution together with the all the unpublished knowledge of the experts and combine it into a single accessible program, which could come in handy whenever a novice, student or practitioner engineer need it. The knowledge is extracted from literatures, questionnaire form and interviews with senior pavement engineers (expert), who have long expertise in flexible pavement engineering, especially in stabilization. The knowledge is then represented in knowledge base and encodes to be suitably entered in expert system builder shell (ES BUILDER). The system after being developed is have then to be evaluated by the experts and the users, to evaluate its efficiency and to recommend improvements and offer suggestions to improve the user interface. The overall commands after the evaluation stated that the software was very favorable. The users were very impressed by the system and it's efficient and solutions for the soil stabilization.
\end{abstract}

Keywords: Expert System, Soil Stabilization, Flexible Pavement, ES Builder.

\section{INTRODUCTION}

$\mathrm{T}$ ransportation in the third world countries basically depended on road network rather than on another facilities such as railway, marine and airways. It is therefore expected that this type of network is exposed to the damaging effects resulting specially from axle load of commercial trucks, in addition to the weather effects. Soil is the basis for all types of constructions, such as buildings, roads, and airports, so all of these constructions need soil with certain engineering properties that are compatible with it. In order to extend the useful life of the fixable pavement, fragile and weak soils must be improved and stabilized to obtain high serviceability level and to decrease the rate of soil deterioration.

Revised Manuscript Received on July 20, 2020.

* Correspondence Author

Mahmood Rashid Mahmood, Civil Engineering, University of Technology, Baghdad, Iraq. E-mail: mahmoudal_qaissy@yahoo.com

Ammar A. M. Shubber, Civil Engineering, University of Technology, Baghdad, Iraq. E-mail: 40162@uotechnology.edu.iq

Asaad Hamdan Maryoosh*, Civil Engineering, University of Technology, Baghdad, Iraq. E-mail: asaad.hamdan@yahoo.com

(C) The Authors. Published by Blue Eyes Intelligence Engineering and Sciences Publication (BEIESP). This is an open access article under the CC BY-NC-ND license (http://creativecommons.org/licenses/by-nc-nd/4.0/)
The diagnosis of soil problems and applying the appropriate solution require a significant amount of engineering judgment. This engineering judgment accumulates during long practice and training period to form an expert. In Iraq, there is lack of experts of soil stabilization under flexible pavement, and experience is limited to few experts. There is also lack in the distribution of these experts.

Therefore, the development of a system that provides expert consultation in the domain of soil under flexible pavement became a real need. The most valuable asset of the system is its availability, as it can be used at any time or place wherever experience is required, minimizing the necessity of consulting a human expert.

\section{OBJECTIVE OF THE STUDY}

Based on the formulation of the problem of the current research, the main objective of the study is formulated in a few stages. The first would be the classification of the soil and its properties under flexible pavement according to the available literature and expert's opinion, alongside their suitable remedies. The construction of a knowledge base that incorporates the gathered information in a form of rules, suitable to be implemented in an expert system environment of -a diagnostic- advisory nature. Then the developing of an expert system for soil stabilization under the flexible pavement that can be provided an advice about soil stabilization and can be used by practicing highway engineers to overcome problem in this domain. After that a validation is needed of the developed system through an extensive evaluation process in a real environment by both experienced and practicing engineers. Finally, determining the system after development to be used as an assistant tool to practicing engineers or instruction system to the novice engineers through the repeated use of the program.

\section{SOIL STABILIZATION}

The essential idea of providing a soil with the suitable engineering criteria and/or modified materials; to perform as a foundation for a certain function, is not recent. [1] Humanity had to come with an alternative method, which materialized with the "Macadam" roads, rubble or gravel-topped roads which was used in the 1850s for the first time in the American continent. [2] In the 1900s adding infilling materials was employed for seepage control and dam building especially the gravelly and the rockfill types in Egypt, the gaps between the coarse aggregate was filled with a fine soil to reduce permeability.

Published By:

Blue Eyes Intelligence Engineering and Sciences Publication

(C) Copvriaht: All riahts reserved.

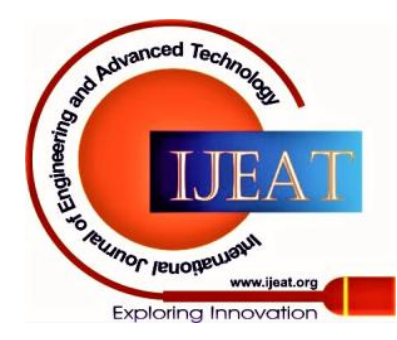




\section{Developing Expert System for Soil Stabilization under Flexible Pavement}

Then experiments took a high curve, producing the first experiment of the sand-clay mixture in the United States in 1906, this experiment was met with a high skeptically from the engineers at that time, but to meet the high increase of the motor in Europe in the 1930s, vehicle traffic,

the wide acceptance of the soil stabilization for road construction was widely endorsed. [3]

The purpose of soil and ground improvement is essentially to alter the natural properties of soil (and/or rock) and control the behavior of a geotechnical features or earthwork in order to improve the behavior and performance of a project. Among the properties that are usually targeted for improvement are: [1]

1. Reducing compressibility to avoid settlement.

Increasing strength to improve stability, bearing capacity, or durability.

2. Reducing permeability to restrict groundwater flow.

3. Increasing permeability to allow drainage.

4. Lowering the potential of (earthquake-induced) liquefaction.

according to [4], the first classification type was based on the character of the techniques and, accordingly, three main categories can be distinguished:

1. Mechanical methods which ensure soil stability without the addition of any foreign material. Thus the soil properties can be improved.

2. Physical methods: which is altering the physical properties of the soil.

Chemical methods: The chemical reactions such as ion exchange, Precipitation, Polymerization and Oxidation.

\section{EXPERT SYSTEM}

Nowadays, expert systems are increasingly applied in different domains to solve complex real-world problems, which are traditionally solved using expert human judgment and experience. Many industrial and governmental organizations especially in Europe and the United States are now applying this new technology to solve problems and go towards their projected own objectives. [5]

A definitions of many, regarding the expert system is "Programs capable of expert-level-performance in specialized fields". [6]

It is known that Expert System is different than other types of programs, due to the knowledge of the application area of the expert systems being separated logically and physically from the reasoning or inference mechanism. [5]

The expert system is also depending on knowledge and capable of performing reasoning. The reasoning that is performed in an expert system, is an attempt to imitate human expert in the combining of the pieces of knowledge. The components of the expert system structure according to [7] are:

1. Knowledge Acquisition Facility.

2. Knowledge Base.

3. Inference Engine.

4. User Interface.

Expert system techniques are used in various Fields, such as medical, industrial, economic and civil engineering, and the main application of the express systems can be classified as follows: [8]
1. Diagnosis
2. Selection
3. Advisory
4. Monitoring and Control
5. Interpretation of data
6. Prediction
7. Design
8. Planning

\section{METHODOLOGY}

\section{A. Theoretical survey}

This stage deals with the comprehensive review of specialized books, reports, papers, manuals and other written sources in the field of soil stabilization laying under flexible pavement, and it was performed by the researcher to construct the initial form of the required knowledge base.

\section{B. Experience acquisition}

During this stage detailed and thorough interviews with the selected number of experts were made, to obtain the required domestic knowledge in the diagnosis of the properties of the soil and the remedies for its deficiency.

\section{Model building}

The information gathered in the first and second stages were used, after representation and encoding process, to build an expert system that can be easily accessed by practicing highway engineers to obtain the required consultation with minimum constraints of time and cost.

\section{Model evaluation}

Final stage, the developed system was subjected to extensive consultation sessions in order to test its efficiency and performance in solving different type of domain problems.

\section{PROGRAM IN OPERATION}

These pictures are examples for the program during operation:

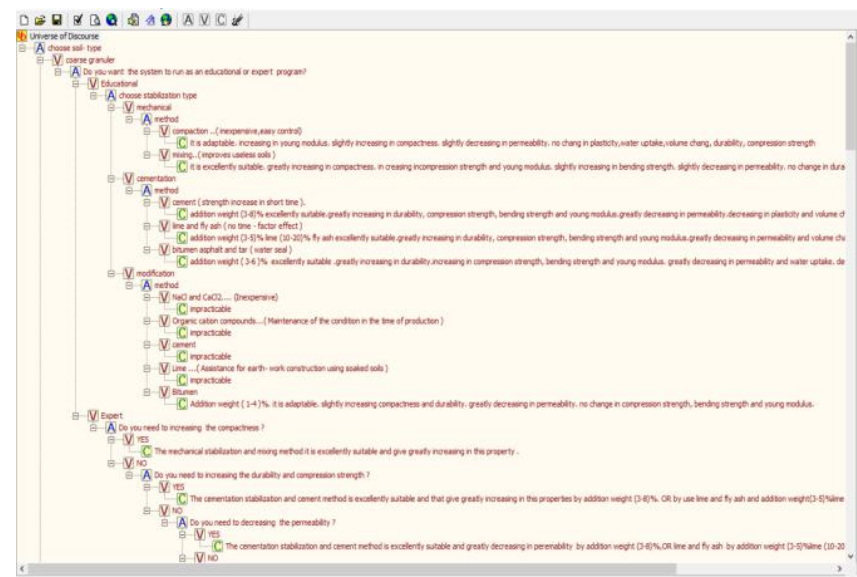

Fig. 1. Sample of the tree of the program fed with information

Published By:

Blue Eyes Intelligence Engineering and Sciences Publication

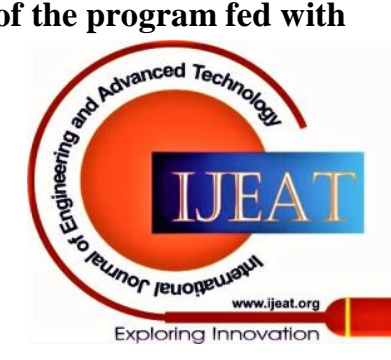




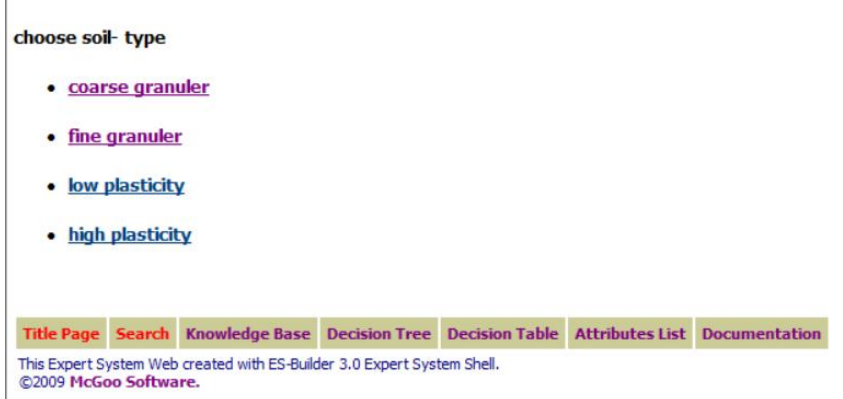

Fig. 2. The first step of the program while it asks about the soil type

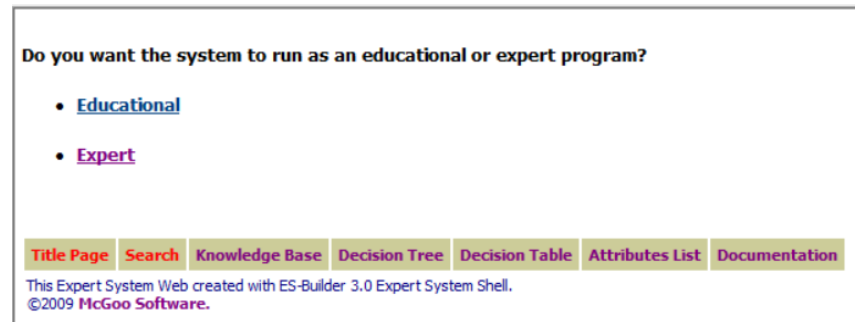

Fig. 3. The part where the user chooses either to use "Educational" or "Expert"

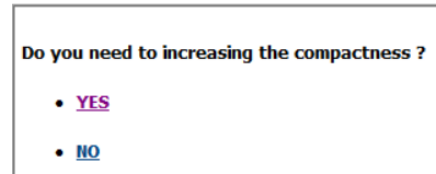

\begin{tabular}{|l|l|l|l|l|l|l|} 
Title Page & Search & Knowledge Base & Decision Tree & Decision Table & Attributes List & Documentation
\end{tabular} This Expert System Web created with ES-Builder 3.0 Expert System Shell.
Q2009 MoGoo Software.

Fig. 4. The program ask about the preferences of the soil in question

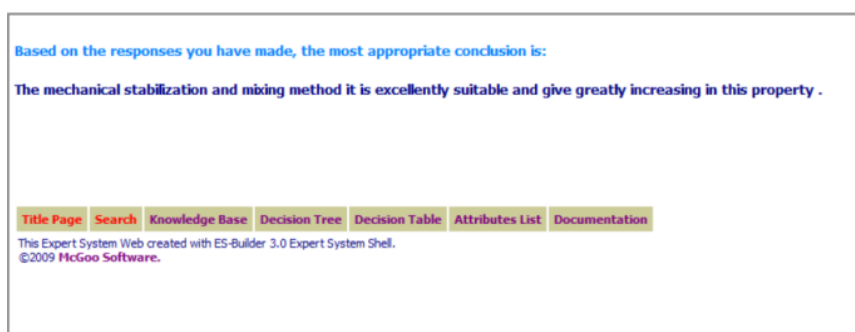

Fig. 5. The conclusion that is given by the program after asking a sufficient number of questions

\section{RECOMMENDATIONS}

The following recommendations could be considered for improving the developed system ES3 as well as improving the ways of stabilization under flexible pavement:

1) There is a need to develop an Iraqi stabilization manual compatible with the available material, equipment, Iraqi traffic, climatic factors and soil types.

2) The quality control for the stabilization procedure and the stabilization materials has to improve.

3) Using the developed "ES3" system as an educational system and a training tool. The educational value is significant in using any kind of expert system; the student will gain some familiarity with an important and rapidly growing computer application. The system will assist the student to understand the logic and the technical background of the stabilization. On the other hand the system can transfer the experts' knowledge, which are often not available to provide the analytical advice to the novice engineer, thus the program works as a training tool.

\section{CONCLUSION}

The following conclusions can be drawn from the research field work and the development of "ES3"

1) The general benefits of ES3 may be summarized in the following points:

a) Providing expert knowledge on soil stabilization under fixable pavement during construction and its planning for less experienced and inexperienced engineers especially when experts are not available or very expensive to be consulted. in addition, the system can assist to excite the expert's interest with new ideas.

b) Time will be saved in waiting for expert to find the best suitable stabilizer for the soil.

c) The system can be used as an educational aid (or teaching program) to train the novice engineers on how to use the different methods of stabilization with different soil types.

d) The system must be used as a tool to assist users, rather than to replace human expert, because no matter how efficient the expert system is, it is still limited in knowledge base and requires updating.

e) The updating process must be done by knowledge engineer or an expert, who is familiar with the expert system shell, and has real new information to modify the existing knowledge base. The knowledge is an accumulation of imagination, judgment, and reasoning which are found in human experts and must be elicited from them first, and then encoded as a computer program.

f) The development system works on PC computer as minimum requirement, and can be saved on USB flash, therefore, it is easy to handle and can be used in many location to minimize costs and delays.

2) During the knowledge collection from the expert, it was noticed that there is a lack stabilization techniques because there is no direct Iraqi soil stabilization manual contains the suitable remedies according to the Iraqi traffic, climatic factors and soil types. The developed system may provide such stabilization manual information with more flexible way.

There is a lack in expert's distribution. Developing a diagnostic expert system, to be used as a guideline, provided a great assistant.

\section{REFERENCES}

1. P. G. Nicholson, Soil Improvement and Ground Modification Methods. Butterworth Heinemann is an imprint of Elsevier, 2014.

2. A. Kezdi, Stabilized Earth Roads. Budapest: Elsevier Scientific Publishing Company, 1979.

3. J. A. Charles, "Ground Improvement: The Interaction of Engineering Science and Experience-Based Technology," Geotechnique, vol. 52, no. 7, pp. 527-532, May 2002, doi: 10.1680/geot.2002.52.7.527.

Published By:

Blue Eyes Intelligence Engineering and Sciences Publication

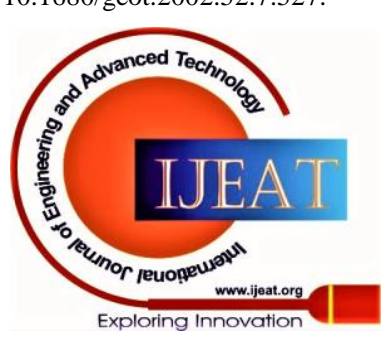




\section{Developing Expert System for Soil Stabilization under Flexible Pavement}

4. T. S. Amhadi and G. J. Assaf, "Overview of Soil Stabilization Methods in Road Construction," Springer, Cham, 2019, pp. 21-33.

5. K. Parsaye and M. Chignell, Expert Systems For Experts. Wiley; 1 edition, 1988.

6. R. J. Allwood, Techniques and Applications of Expert Systems in The Construction Industry. Halsted Press, 1989.

7. Y. Oshima, Information Control Problems in Manufacturing Technology. IFAC International Symposium, Tokyo, Japan, 1978.

8. C. S. Battu, "Design of NIPFI: an Advisory Expert System for $\mathrm{R} \cdot$ Leasurement and Improvement of Productivity of Foodservice Industries," 1989.

\section{AUTHORS PROFILE}

Dr. Mahmood R. Mahmood was born in Diyala, Iraq in 1960; he received the B.Sc. degree in Building and Construction Eng., from the University of Technology, Iraq in 1982, and the M.Sc. degree in soil Mechanics from Herriot -Watt University, Edinburgh-Scotland U.K in 1987. He received his Ph.D degree in Geotechnical engineering from Al-Rasheed College, University of Technology, Iraq in 2001. He is currently an Assist. Professor at the Department of Civil, University of Technology, Iraq.

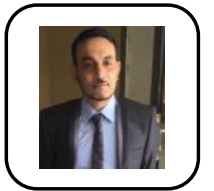

Dr. Ammar A.M. Shubber, was born in Baghdad Iraq in 1972, he received his B.Sc. degree in Building and Construction Engineering, from the University of Technology, Iraq in 1996, and the M.Sc. degree in Highway and Airport engineering from the University of Technology, Iraq in 2000, He received his Ph.D. degree in Roads and Railway engineering at Southwest Jiaotong University, Chengdu, China in 2008. He is currently a Lecturer at the Department of Civil engineering, University of Technology, Iraq.

Asaad Hamdan Maryoosh*, he was born in 1985 in Baghdad, Iraq. He got his B.Sc. in civil engineering from University of Technology, Baghdad, Iraq, 2011. And applied to the M.Sc. degree in 2017 in the same university.

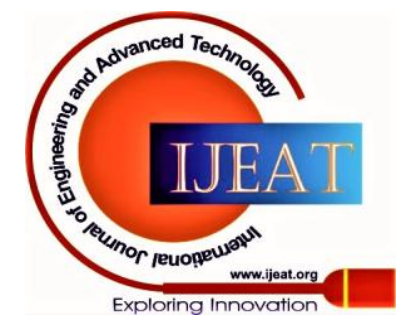

